\title{
TECNOLOGIAS DA INFORMAÇÃO E COMUNICAÇÃO NA MUDANÇA DA MOBILIDADE URBANA NA REGIÃO METROPOLITANA DE SÃO PAULO, SP
}

\author{
Roberta B. F Squaiella ${ }^{1}$
}

Maria Victoria Marchelli ${ }^{2}$

Roberto Righi ${ }^{3}$

\begin{abstract}
RESUMO
$\mathrm{Na}$ urbanização das cidades, as questões da acessibilidade e mobilidade urbana são fatores essenciais. A partir do século XX, realizaram-se importantes planos urbanísticos na RMSP, em que destaca-se o uso do automóvel, como grande papel para o desenvolvimento regional metropolitano, apesar de gerar novas questões econômicas, sociais, culturais e territoriais. Os órgãos governamentais precisam equacionar a locomoção diária de mais de 20 milhões de habitantes (IBGE, 2014) da RMSP. O objetivo principal deste trabalho é apresentar mudanças nos padrões de mobilidade recente da RMSP, algumas já associadas às novas tecnologias da informação e comunicação. A análise é feita com informações da Pesquisa de Mobilidade (2012), com dados de 2007 e 2012. No seu desenvolvimento, os conceitos de mobilidade, acessibilidade e o uso das novas tecnologias atuais são definidos e avaliados. Como resultado conclui-se, de forma crítica, o porquê do aumento menor, do total de viagens realizadas, no modo de transporte coletivo em relação ao individual, $16 \%$ e $21 \%$, respectivamente. No último, as motos ganham destaque e desempenham papel importante na entrega de produtos de transações realizadas por meio da internet. A população de maior renda passou a aderir mais ao transporte público. Finalmente, as novas tecnologias da informação e comunicação, ainda engatinham, mas já indicam novas relações de comércio e serviços, com alteração da mobilidade urbana e compartilhamento de informações, contribuindo para a economia de energia e preservação dos recursos, em uma sociedade mais conectada, ativa e participativa.
\end{abstract}

\footnotetext{
1 Mestranda em Arquitetura e Urbanismo, Universidade Presbiteriana Mackenzie. Email: robssquaiella@gmail.com.

2 Mestranda em Arquitetura e Urbanismo, Universidade Presbiteriana Mackenzie. Email: victoria.marchelli@gmail.com.

3 Arquiteto e Urbanista, Professor titular da Universidade Presbiteriana Mackenzie. Email: roberto.righi@mackenzie.br
} 
Revista Nacional de

Gerenciamento de Cidades

PALAVRAS-CHAVE: Mobilidade urbana. Tecnologia. Região Metropolitana de São Paulo (RMSP).

\title{
INFORMATION TECHNOLOGY AND COMMUNICATION IN CHANGE URBAN MOBILITY IN THE METROPOLITAN REGION OF SÃO PAULO, SP
}

\begin{abstract}
In the urbanization of cities, issues of accessibility and urban mobility are essential. From the 21th century, important urban plans were made in the RMSP, where the car stands out, as a big role for metropolitan regional development, despite generating new economic, social, cultural and territorial issues. Government agencies need to equate the daily mobility of over 20 million inhabitants (IBGE, 2014) in the RMSP. The aim of this paper is to present recent changes in mobility patterns of RMSP, some already associated with new technologies of information and communication. The analysis is done according to the Pesquisa de Mobilidade (2012), with 2007 and 2012 data. In its development, the concepts of mobility, accessibility and the use of recent new technologies are defined and evaluated. As a result we conclude, critically, the reason of the smallest increase, of total trips made on public transport mode in relation to the individual, $16 \%$ and $21 \%$, respectively. At last, the motorcycles are highlighted and play an important role in the delivery of goods carried out through Internet transactions. The population with higher incomes started to adhere more to public transportation. Finally, the new technologies of information and communication, still are growing, but already indicate new relations of trade and services, with changes in urban mobility and information sharing, contributing to saving energy and conserving resources in a more connected, active and participatory society.
\end{abstract}

KEY-WORD: Urban Mobility. Technology. São Paulo Metropolitan Region (RMSP)

\section{TECNOLOGÍA DE LA INFORMACIÓN Y LA COMUNICACIÓN EN CAMBIO MOVILIDAD URBANA EN LA REGIÓN METROPOLITANA DE SÃO PAULO, SP}

\begin{abstract}
RESUMEN
En la urbanización de las ciudades, los problemas de accesibilidad y movilidad urbana son esenciales. A partir del siglo XX, se realizaron importantes planos urbanos en la RMSP, donde se destaca el uso de automóvil, como gran papel para el desarrollo regional metropolitano, aunque genera nuevas cuestiones económicas, sociales, culturales y territoriales. Las agencias gubernamentales tienen que equiparar la movilidad diaria de más de 20 millones de habitantes (IBGE, 2014) en la RMSP. El objetivo del trabajo es presentar los cambios recientes en los estandars de movilidad de RMSP, algunos ya asociados con las nuevas tecnologías de información y comunicación. El análisis se realiza de acuerdo a la Pesquisa de Mobilidade (2012), con datos de 2007 y 2012. En su desarrollo, los conceptos de movilidad, accesibilidad y el uso de nuevas
\end{abstract}




\section{Revista Nacional de}

Gerenciamento de Cidades

tecnologías serán definidos y evaluados. Como resultado se concluye, de manera crítica, el motivo de menor incremento, del total de viajes realizados en el modo de transporte público en relación con el individual, $16 \%$ y $21 \%$, respectivamente. Por fin, las motocicletas se destacaron y desempenãn un papel importante en entregas de transacciones de Internet. La población con mayores ingresos pasó a adherirse más al transporte público. Por último, las nuevas tecnologías de información y comunicación, todavía están cresciendo, pero ya indican nuevas relaciones de comercio y servicios, con cambios en la movilidad urbana y intercambio de informaciónes, contribuyendo para la economia de energía y conservación de recursos, en una sociedad más conectada, activa y participativa.

PALABRAS-CLAVE: Movilidad urbana. Tecnología. Región Metropolitana de São Paulo (RMSP).

\section{INTRODUÇÃO}

Atualmente as cidades tem se tornado palco de novas transformações e discussões. A partir do século XX houve um grande crescimento da população urbana mundial, sendo que em 2007 , metade desta população $(50 \%)$ passou a residir nas cidades (ONU, 2007). Mais recentemente, o número de automóveis alcançava 1.015 bilhões em 2010 (SOUSANIS, 2011). O automóvel passou a desempenhar um importante papel no transporte e meio urbano contemporâneo, viabilizando novas e mais dispersas conformações, apesar de existirem grandes controvérsias acerca de seu uso, numa complexa relação entre a urbanização e a motorização (DUPUY, 1995).

Aprofundando os conceitos urbanísticos, pode-se afirmar que, em contraposição às cidades tradicionais, as quais possuíam uma estrutura monocêntrica com forte concentração e polarização das funções urbanas pelo núcleo central, novas centralidades e suburbanização foram formadas nas metrópoles contemporâneas. Através da descentralização de empregos, moradias, educação, comércios e outras funções, acontecem as centralidades em uma estrutura policêntrica, resultante das políticas públicas, das iniciativas privadas, do desenvolvimento das comunicações e de transportes. Neste cenário, destaca-se a importância do automóvel, apesar do seu uso gerar degradação das relações sociais, culturais, do meio ambiente e das áreas urbanas. Esta situação é 


\section{Revista Nacional de}

semelhante a que ocorre na Região Metropolitana de São Paulo que, em sua recente história, destina as suas principais vias para as ligações regionais e os automóveis desempenham papéis importantes na urbanização, principalmente para os segmentos sociais de alto padrão com demanda econômica e poder político agregados. De acordo com Righi e Dinis (2011), na primeira metade do século XX foi estruturado o núcleo central dessa metrópole, orientado pelo Plano de Avenidas Prestes Maia. As próximas expansões ocorreram com a abertura de novas frentes de urbanização, que possuíam caráter descentralizador e favorável ao automóvel, como por exemplo as avenidas Paulista e Faria Lima, as Marginais e o Rodoanel. Também sucederam-se planos urbanísticos como: Moses, SAGMACS, PUB, PDDI e PMDI. A urbanização da cidade tornou-se complexa, com a conjugação de uma região central mais verticalizada e elitizada, e uma periferia mais popular e esparsa, além do desenvolvimento mais recente de novos padrões inovadores de suburbanização. $\mathrm{Na}$ composição das viagens pendulares, o transporte individual, destacando-se o automóvel, torna-se dominante e exige novos posicionamentos da economia urbana, que pode contribuir de modo importante para a sua definição.

De maneira mais geral, nas últimas décadas, todas as cidades brasileiras foram adaptadas para o uso do automóvel, especialmente as maiores. Isso virou parte da cultura no Brasil e correspondeu a um processo de privatização da mobilidade devido, principalmente, aos interesses do governo em estabelecer uma industrialização orientada pelo núcleo do aço, petróleo e automóveis, que fascinou as classes médias. Paralelamente, houve uma crescente negligência para o sistema de transporte público, que afastou a sociedade do seu uso como principal forma de transporte motorizado. Como resultado, há um aumento em congestionamentos e acidentes, com redução de áreas verdes para a criação de maiores vias e estacionamentos, que saturam a circulação urbana, contribuindo nocivamente para a poluição ambiental e sonora, a partir do uso de fontes não renováveis.

As cidades evoluem de acordo com as mudanças técnicas e sociais da sociedade. A interferência das novas tecnologias da informação e comunicação 


\section{Revista Nacional de}

ocorre na reconfiguração dos espaços urbanos e das práticas sociais, regidos pelo tempo real e imediato no mundo global. Novos estilos de vida e, funções cada vez mais ligadas às redes telemáticas, emergem numa maior velocidade. Através dos recursos de geolocalização, um conjunto de dispositivos, sensores e redes digitais sem fio e seus respectivos bancos de dados, possibilitam-se as trocas de relação dinâmica, onde criam-se novos sentidos dos lugares e redimensionam-se as práticas sociais no espaço urbano (LEMOS, 2009). O conceito de compartilhamento, que ressalta o senso de comunidade e resgata práticas sociais cooperativas, permite 0 uso de bens, espaços e serviços de forma coletiva, como o uso compartilhado de espaços de trabalho, de transporte e de veículos alternativos, que possibilitam facilidades na mobilidade urbana, redução do tempo gasto em grandes congestionamentos, redução das grandes distâncias entre a moradia e o trabalho, e a racionalização de despesas e de consumo (SANTOS, 2014).

\section{MOBILIDADE E ACESSIBILIDADE}

Abordar a mobilidade e acessibilidade da cidade é fundamental para garantir melhor qualidade de vida para seus habitantes, além de gerar menores impactos no meio ambiente. $O$ valor de preservar recursos é inestimável para a civilização e, o seu uso adequado, é o que permitirá a sobrevivência da mesma (DIAMOND, 2013).O crescimento acelerado das cidades e dos centros urbanos, paralelamente a descentralização econômica-espacial das atividades, gerou um maior afastamento entre estas, como o morar e trabalhar, resultando em maiores deslocamentos. Segundo Duarte et. al (2012) as esferas organizacional e física atingem, primeiramente, as populações com baixa renda e menos protegidas, onde a acessibilidade ao espaço urbano e a circulação são muito reduzidas. Também, as inovações urbanas têm gerado novos padrões de suburbanização. Pode-se afirmar que a equação cidade, transporte e mobilidade com acessibilidade, conforma a complexidade urbana. 


\section{Revista Nacional de}

Destaca-se dentre as várias definições sobre o conceito de mobilidade urbana: "pode ser entendida como a maior ou menor facilidade de se deslocar entre dois pontos. Quando esse deslocamento tem lugar, em tudo ou em parte, em âmbito urbano, fala-se em mobilidade urbana" (FERRANDIZ, 1990 apud BOCANEGRA, 2002, p.37). No Brasil, a Secretaria Nacional de Transporte e Mobilidade Urbana (SeMob) foi instituída no Ministério das Cidades com a finalidade de formular e implementar a Política Nacional de Mobilidade Urbana, contida na Lei № 12.587, de 3 de janeiro de 2012 (BRASIL, 2012). Nesta, a mobilidade urbana é definida como: "condição em que se realizam os deslocamentos de pessoas e cargas no espaço urbano", e está fundamentada nos seguintes princípios: I - acessibilidade universal; II - desenvolvimento sustentável das cidades, nas dimensões socioeconômicas e ambientais; III - equidade no acesso dos cidadãos ao transporte público coletivo; IV - eficiência, eficácia e efetividade na prestação dos serviços de transporte urbano; $\mathrm{V}$ - gestão democrática e controle social do planejamento e avaliação da Política Nacional de Mobilidade Urbana; VI - segurança nos deslocamentos das pessoas; VII - justa distribuição dos benefícios e ônus decorrentes do uso dos diferentes modos e serviços; VIII - equidade no uso do espaço público de circulação, vias e logradouros; e IX - eficiência, eficácia e efetividade na circulação urbana.

A mobilidade urbana sustentável pode ser definida como o resultado de um conjunto de políticas de transporte e circulação que visa proporcionar o acesso amplo e democrático ao espaço urbano, por meio da priorização dos modos nãomotorizados e coletivos de transportes, de forma efetiva, sem gerar segregações espaciais, socialmente inclusiva e ecologicamente sustentável. "É o resultado da interação entre os deslocamentos de pessoas e bens com a cidade" (BRASIL, 2004, p. 13). Entende-se que a acessibilidade deve ter seu destaque, e que sempre foi fator importante de análise. Pensar a acessibilidade no planejamento urbano significa identificar áreas com desigualdades na oferta de infraestrutura básica. Normalmente, as áreas de menor renda são as que apresentam maiores 


\section{Revista Nacional de}

desigualdades. O conceito de acessibilidade também corresponde a "quantidade e/ou diversidade de destinos que a pessoa consegue alcançar, por certa forma de transporte, em determinado tempo" (VASCONCELLOS, 2012, p.42). Quanto maior for a acessibilidade, maiores são as oportunidades de deslocamento disponíveis, sendo que ela segmenta-se entre macro e microacessibilidade. A primeira, trata-se do trajeto como um todo e a segunda, mede o que acontece quando o individuo está próximo do seu destino.

\section{MOBILIDADE URBANA NA ERA DA CONEXÃO}

Na cidade informacional do século XXI encontra-se a cultura da mobilidade, caracterizada pela mobilidade de pessoas, objetos, tecnologias e informações. A modernidade ampliou as formas de mobilidade, tanto no âmbito físico, com os transportes, quanto no virtual, com os meios de comunicação de massa. Entre a dimensão física e os sistemas de informação, há uma dinâmica a ser explorada, compreendida pelo espaço privado e o público. Por meio das comunicações em rede, as cidades são pensadas como formas de reestabelecer o espaço público e reforçar os laços comunitários de acordo com as diversas inteligências coletivas. Nelas vemos a redefinição dos espaços público e privados, com a potencialização das trocas entre seus cidadãos e a ocupação de espaços concretos. Destaca-se que, dentre algumas questões, exercer cidadania na cidade atual, é estar ligado a uma conexão generalizada por meio das grandes redes de comunicação, desde as "tecnologias nômades" - laptops, tablets e celulares, até as redes de Wi-Fi. É necessário reconhecer a instauração de uma nova dinâmica de reconfiguração do espaço urbano, que possibilite formas efetivas de comunicação e de reapropriação do espaço físico, reaquecendo o espaço público, e fortalecendo a democracia contemporânea (LEMOS, 2005). 


\section{Revista Nacional de}

\section{O AUTOMÓVEL E O SEU IMPACTO PARA AS CIDADES}

O automóvel é uma invenção do final do século XIX e o seu aperfeiçoamento foi determinante na sua relação com a cidade. Para manter-se atuante, as indústrias automobilísticas progridem com os incentivos fiscais do governo. Devido a primazia do automóvel, as políticas públicas das grandes cidades se submetem a circulação individual de pessoas, que é responsável pela degradação de extensas áreas urbanas e das relações sociais e culturais (RIGHI; DINIS, 2011).

No estudo Perfil da Mobilidade Urbana no Brasil - 2003 (ANTP; BRASIL, 2004), elaborado em conjunto pela Associação Nacional de Transportes Públicos (ANTP), Ministério das Cidades e o Banco Nacional do Desenvolvimento (BNDES), foi possível estimar resultados para o consumo de energia, emissão de poluentes e custo de acidentes para o conjunto de cidades com mais de 60 mil habitantes. $\mathrm{Na}$ questão de energia, foi constatado que consome-se 10,7 milhões de TED (Tonelada Equivalente de Petróleo) por ano na realização da mobilidade urbana, sendo $75 \%$ no transporte individual e $25 \%$ no transporte coletivo. Dessa forma, a poluição produzida pelo transporte individual custa à sociedade o dobro da produzida pelo transporte público. Ainda que o automóvel tenha passado por sucessivas crises petrolíferas e o preço do combustível aumentado, ele não dever ser totalmente abandonado, mas sim corretamente articulado com modos de circulação coletiva (RIGHI; DINIS, 2011).

\section{SUBURBANIZAÇÃO E MOBILIDADE}

Há uma estrutura policêntrica nas metrópoles contemporâneas, que está relacionada com as novas políticas públicas, os novos empreendimentos e às mudanças tecnológicas na comunicação e nos transportes, que diminuem a dependência da região metropolitana ao núcleo central. Esse processo começou a surgir inicialmente nos Estados Unidos, devido ao aumento de acessibilidade 


\section{Revista Nacional de}

proporcionado pelo automóvel, além de outros fatores como: problemas urbanos na região central, aumento da renda, diminuição nos custos de deslocamento, acompanhamento do emprego, uso das novas tecnologias da informação e comunicação, favorecimento de políticas públicas para a aquisição imobiliária e infraestrutura regional (RIGHI; DINIS, 2011).

Destaca-se que, o uso das novas tecnologias da informação e comunicação, impactam em mudanças nas relações de emprego e, consequentemente, na circulação nas cidades, visto que o seu uso possibilita, inclusive, o desmembramento das empresas. Isso ocorre devido a grande importância da relação entre emprego e população, que impulsionam as mudanças no desenvolvimento do comércio, nos deslocamentos a trabalho, e no uso do automóvel. A aglomeração de atividades e a partilha coletiva de infraestrutura são bases importantes para a urbanização. A diminuição da aglomeração nos centros urbanos reflete-se no crescimento do transporte individual, pois a motorização individual surge quando a dispersão urbana é excessiva, e inviabiliza o deslocamento a pé e a presença viável do transporte coletivo. Atualmente, nos países desenvolvidos, o uso do automóvel é desestimulado nas áreas centrais, devido a políticas urbanas que valorizam o pedestre e o transporte coletivo, contra 0 emprego do veículo individual (LAMURE, 1995).

\section{ANÁLISE DA MOBILIDADE DA REGIÃO METROPOLITANA DE SÃO PAULO}

A RMSP compreende 39 municípios em uma área de $8.047 \mathrm{~km}^{2}$ (EMPLASA, 2011), possui mais de 20 milhões de habitantes (IBGE, 2014) e aproximadamente 8,2 milhões de automóveis (DENATRAN, 2015). Atualmente, a rede de metrô alcança 66,2 km (METRÔ, 2015) de extensão e a rede de trem metropolitano, 260,8 km (CPTM, 2014), o qual divide-se entre cargas e passageiros.

Com base na Pesquisa de Mobilidade da RMSP (SÃO PAULO, 2012), analisam-se os intervalos entre origem e destino nas viagens diárias, e quais meios 


\section{Revista Nacional de}

de transporte são utilizados para tal. Verifica-se que, desde a primeira pesquisa de origem e destino em 1967, ocorreu uma inversão entre o modo de transporte coletivo e individual. Em 1967, as viagens por modo coletivo abrangiam $68 \%$ do total de viagens motorizadas. No decorrer dos 35 anos seguintes, a participação das viagens por modo coletivo começou a decrescer até que, em 2002, o modo individual predominou. A situação voltou a se estabilizar em 2007, quando o modo coletivo ultrapassou novamente o individual. Essa situação manteve-se estável até 2012, sendo $54 \%$ para modo coletivo e $46 \%$ para individual, indicando um processo de mudança em curso, que pode no futuro até trazer um reforço do transporte coletivo em detrimento do individual. Entre 2007 e 2012, a população teve um crescimento populacional de $2 \%$, totalizando 20 milhões. A taxa de emprego também sofreu alterações, subindo para $8 \%$ e as matrículas escolares aumentaram $2 \%$, conforme indicado na figura 1 .

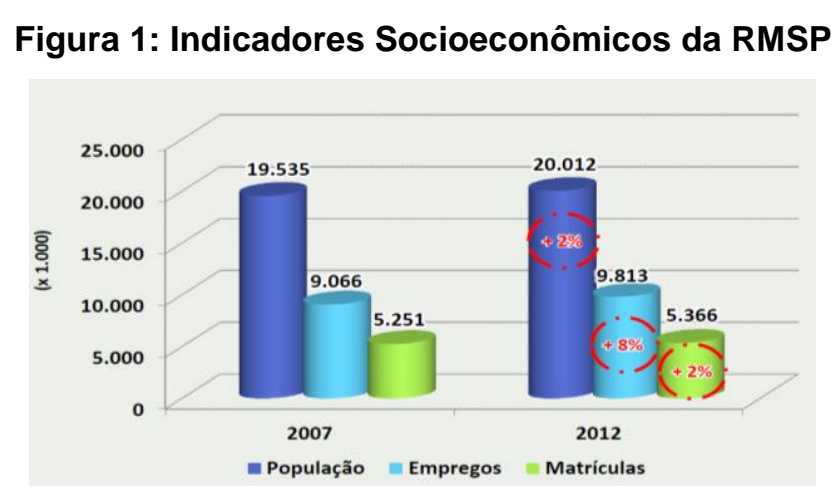

Fonte: Pesquisa Mobilidade 2012, 2012, p.14

Percebe-se a correlação entre as viagens diárias e os indicadores socioeconômicos que, devido ao crescimento da população e dos novos empregos, ocorreu um aumento de $15 \%$ das viagens diárias. Foram contabilizadas 43,7 milhões de viagens diárias na RMSP, realizadas por todos os modos. Desse total, 29,7 milhões foram viagens realizadas por modo motorizado, resultando no aumento de $18 \%$, e 14 milhões por modo não motorizado, crescendo percentualmente $8 \%$. As 


\section{Revista Nacional de}

viagens por modo coletivo evoluíram $16 \%$, e as por modo individual, $21 \%$. Ocorreu também, o aumento de viagens motorizadas pela população de renda mais baixa. Já a população de maior renda, teve uma significativa diminuição nas viagens motorizadas, e acréscimo do modelo coletivo (Ver tabela 1). A conclusão, ainda preliminar a ser sujeita a comprovações mais detalhadas, é que são esses segmentos sociais superiores que podem escolher as melhores localizações urbanas, além de utilizarem mais os novos meios eletrônicos de comunicação, diminuindo as viagens através de sua substituição pela internet e congêneres.

Tabela 1: Resumo de dados - Renda

\begin{tabular}{lccccc}
\hline \multicolumn{1}{c}{ Item } & \multicolumn{2}{c}{ Resultado em 2012 colunas } & \multicolumn{2}{c}{$\begin{array}{c}\text { Variação em pontos } \\
\text { percentuais (2012/2007) }\end{array}$} \\
\hline Renda (R\$ out/2012) & coletivo & individual & total & coletivo & individual \\
\hline Até 1.244 & $74,8 \%$ & $25,2 \%$ & $100 \%$ & -2 & +2 \\
1.244 a 2.488 & $69,6 \%$ & $30,4 \%$ & $100 \%$ & -2 & +2 \\
2.488 a 4.976 & $51,1 \%$ & $48,9 \%$ & $100 \%$ & -4 & +4 \\
4.975 a 9.330 & $34,2 \%$ & $65,8 \%$ & $100 \%$ & +1 & -1 \\
Mais de 9.330 & $24,1 \%$ & $75,9 \%$ & $100 \%$ & +6 & -6 \\
\hline
\end{tabular}

Fonte: Autores, 2015 com base em Pesquisa Mobilidade 2012, 2012, p.68

Por outro lado, ocorreu um incremento de $45 \%$ no modo metrô e de $62 \%$ no modo trem. Porém o ônibus, com seu crescimento de $13 \%$, e o automóvel com $19 \%$, foram os meios mais utilizados para os deslocamentos, tendo como principal motivo viagens a trabalho, seguindo de educação, compras, saúde, lazer e assuntos pessoais (Ver figura 2). Destaca-se o horário do meio dia como tendo o maior pico de viagens, cerca de 5 milhões de pessoas, e sobressai-se o deslocamento a pé. 


\section{Revista Nacional de} Gerenciamento de Cidades

Figura 2: Viagens por modos motorizados na RMSP

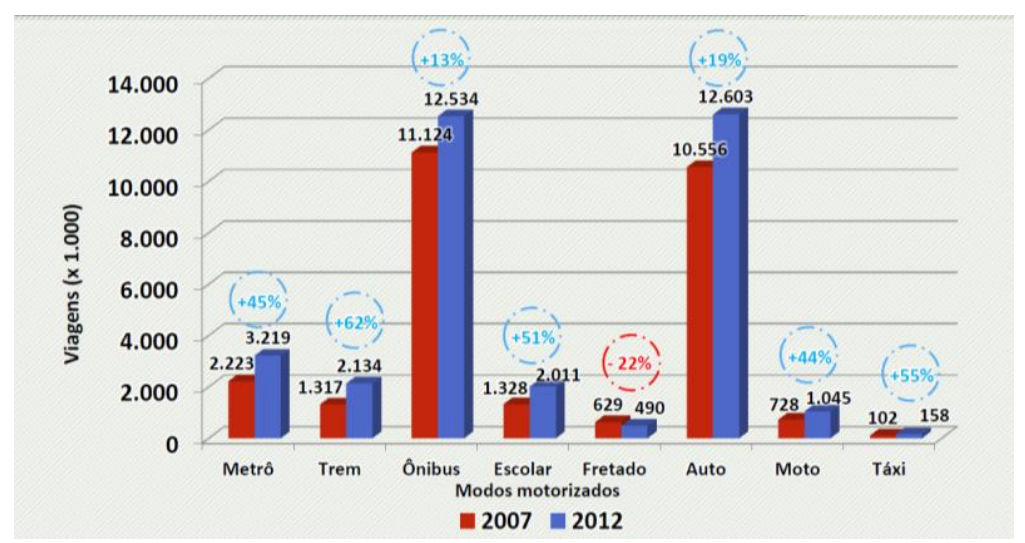

Fonte: Pesquisa Mobilidade 2012, 2012, p.36 ${ }^{4}$

\section{DISCUSSÃO DOS RESULTADOS}

$\mathrm{Na}$ RMSP, os órgãos governamentais não conseguem solucionar de forma adequada a locomoção diária de todos os seus habitantes. Em termos porcentuais, considerando o total de viagens realizadas, o acréscimo de $21 \%$ de viagens no modo de transporte individual, entre 2007 e 2012, supera o aumento de 16\% no coletivo, sendo preocupante essa aparente tendência da mobilidade metropolitana. Porém, uma análise mais detida, mostra que este resultado é apenas sinal da incompetência de diversos municípios em responder a questão, de responsabilidade preponderante deste nível de governo, na velocidade e qualidade necessária da mudança. $\mathrm{Na}$ realidade, a composição do transporte coletivo teve menor crescimento (16\%), principalmente pela queda da representatividade dos ônibus, que mesmo assim cresceram $13 \%$, com novos corredores, porém frota envelhecida e obsoleta, numa rede que exige escala adequada, com maior número e hierarquia de terminais e integração modal. Mostra incontestável de que é possível ter respostas mais corretas e efetivas, é o crescimento acentuado dos usuários do

\footnotetext{
${ }^{4}$ A soma de viagens por modo, nessa tabela, é maior que as viagens realizadas (43,7 milhões) porque cada viagem pode envolver até quatro modos. Destaca-se essa figura para ilustração dos modos motorizados.
} 


\section{Revista Nacional de}

sistema de trilhos, tanto do metrô, como da ferrovia, que cresceram nesse período, $45 \%$ e $62 \%$, respectivamente, resultado de ações ainda em curso do Governo paulista, que tomou iniciativa na questão, apesar do apoio insuficiente do nível Federal. Também é destacado o crescimento dos modos complementares como: transporte escolar que cresceu $51 \%$ e o táxi teve incremento de $55 \%$. O único contraste é o transporte fretado que diminuiu $22 \%$, resultado de providências errôneas da Prefeitura de São Paulo, que dificultaram a sua operação, neutralizando um sistema com capacidade limitada, mas bastante importante, e que não onera os cofres públicos, pois é totalmente privatizado. No transporte individual, o aumento foi de $21 \%$, conforme já apontado, porém o do automóvel foi de $19 \%$. Na realidade, a diferença decorre do grande incremento das motocicletas que cresceram $44 \%$. Elas hoje desempenham um papel fundamental no funcionamento do comércio eletrônico, na entrega de encomendas e pequenas cargas, compradas pelo telefone e internet.

Ainda em relação ao transporte por automóveis, como resultado dos diversos subsídios fiscais liberados pelo governo, a compra de veículos tornou-se fácil e atrativa. Assim, cresceu mais o número de carros nas ruas do que de gente e emprego na RMSP. Porém, a realidade mostra a dificuldade em circular com eles. De acordo com Duarte et. al (2012, p.1), "O transporte deve ser um assunto mais político do que técnico, uma vez que decisões do governo em diferentes escalas, da nacional à local, repercutirão na qualidade de vida da população, de acordo com o modelo adotado." Dessa forma, o Governo pode ceder às pressões imediatas das montadoras, porém deve desenvolver políticas públicas de transporte coletivo para médio e longo prazo. $\mathrm{O}$ acréscimo do modo coletivo representa uma nova forma de abordar os deslocamentos. O meio coletivo ganhou destaque na população de renda mais alta, começando a diminuir as barreiras segregadoras e garantindo melhor acessibilidade e inclusão social. No entanto, o transporte público precisa ganhar importância, eficiência e confiabilidade. 


\section{Revista Nacional de}

Voltando-se ao uso das novas tecnologias da informação e comunicação é relevante abordar os aplicativos empregados na RMSP. A Prefeitura do Município de São Paulo tem incentivado e desenvolvido aplicativos que auxiliam na mobilidade urbana, colaborando na diminuição da emissão de poluentes diretos (ambientais) e indiretos (sonoros). Como exemplo do aplicativo, é possível observar o tráfego nas ruas em tempo real, estimar a rota de percurso e o tempo para os deslocamentos de carro, de ônibus e de bicicleta. Apesar da representatividade ínfima das bicicletas nas viagens na RMSP, destaca-se que com a implantação das ciclovias, desde 2014, já estão sendo desenvolvidos aplicativos, com base no mapa altimétrico da prefeitura, para simulação das rotas, considerando os aspectos como o relevo da cidade, que possui pontos de grandes ladeiras, e a presença de vias exclusivas para os ciclistas (VALLE, 2014). Porém, o mais importante é a atuação de seus habitantes que podem interagir e produzir informações em tempo real, apontando as situações de cada momento. Essa tecnologia pode ser pensada como um laboratório para o seu emprego nos demais modais de transportes da cidade.

\section{CONSIDERAÇÕES FINAIS}

A política de mobilidade da RMSP mostra-se insustentável devido a supremacia do modo motorizado e individual, a falta de extensão dos modos de transporte de massa, dos congestionamentos e a poluição gerada. Destaca-se que a interferência das novas tecnologias da informação e da comunicação na sociedade contemporânea devem atingir, de forma cada vez mais intensa, o desenvolvimento das cidades, e a RMSP não deve fugir à regra. Os recursos informatizados podem trazer melhorias para o espaço urbano, principalmente na mobilidade urbana, com o compartilhamento de informações, possível em uma sociedade mais equipada e consequentemente mais conectada, ativa e participativa. Atualmente, há uma clara tendência pela internet móvel, acessível por simples celulares. O uso das novas 


\section{Revista Nacional de}

tecnologias na concepção e gestão da infraestrutura urbana, leva ao desenvolvimento mais sustentável das cidades, com maior articulação com as estruturas territoriais, o Governo, as empresas e os habitantes.

$\mathrm{Na}$ RMSP, a sociedade precisa aperfeiçoar essa articulação, focando-se nas questões mais amplas que superam apenas o transporte individual, pensando no futuro, repleto de novas tecnologias de informação e comunicação emergentes que trazem novo potencial. A vida dos habitantes melhora, mas também a sustentabilidade. É dada mais prioridade aos problemas ambientais e a utilização racional de recursos de energia e fontes não renováveis.

Dentro deste contexto, a utilização do automóvel na RMSP é um fator importante, que deve ser tratado sem preconceitos, mas seu uso deve ser articulado com outros meios de transporte para garantir melhor qualidade urbana e de vida. Esta articulação deve ser aprofundada e dinamizada, em tempo real, através do progressivo uso das novas tecnologias de informação e comunicação. Devem ser formuladas novas propostas de uso e ocupação do solo, e também de transportes, com uma articulação de políticas públicas e ações privadas, que visam melhorar os aspectos de urbanização, aglomeração e escala. A interferência das novas tecnologias impacta em mudanças no uso dos bens, serviços, e na mobilidade urbana, visto que a utilização do ciberespaço propicia o compartilhamento de dados e informações que contribuem para a economia de energia e preservação dos recursos naturais. A mobilidade urbana, para tornar-se sustentável, deve ser desregulamentada progressivamente de forma a potencializar as tecnologias referidas, conjugando o privado, mantendo os interesses públicos, de maneira a permitir melhores deslocamentos com menores impactos ambientais. 


\section{Revista Nacional de}

\section{REFERÊNCIAS BIBLIOGRÁFICAS}

ANTP, Associação Nacional de Transportes Públicos; BRASIL, Ministério das Cidades. Perfil da Mobilidade Urbana no Brasil - 2003. ANTP, Ministério das cidades. 2004

BOCANEGRA, C.W.R. Procedimentos para tornar mais efetivo o uso das Redes Neurais Artificiais em Planejamento de Transportes. Dissertação (Mestrado), EESC/USP, São Carlos. 2002

BRASIL. Ministério das Cidades. Caderno PlanMob: Construindo a cidade sustentável: caderno de referência para elaboração de Plano de Mobilidade Urbana. Brasília, 2007.

BRASIL. Ministério das Cidades. Lei 12.587- Política Nacional de Mobilidade Urbana. Diário Oficial da União: Seção 1, 4/1/2012, Pág. 1. 2012.

CPTM, Companhia Paulista de Trens Metropolitanos. Relatório da Administração 2014. 2014. Disponível em: <http://www.cptm.sp.gov.br/a-companhia/BalancosDemonstrativos/CPTM\%20\%20Relatório\%20da\%20Administração\%202014\%20-\%20FINAL.pdf>. Acesso em: 24 abri.2015.

DENATRAN, Departamento Nacional de Trânsito. Frota de veículos, por tipo e com placa, segundo os Municípios da Federação - FEV/2015. 2015

DIAMOND, Jared. Colapso: Como as sociedades escolhem o fracasso ou sucesso. 9 ed.- Rio de Janeiro: Editora Record Ltda, 2013.

DUARTE, Fábio; SÁNCHEZ, Karina; LIBARDI, Rafaela. Introdução à mobilidade urbana. 3ed.Curitiba: Editora Juruá, 2012.

DUPUY, Gabriel. L'auto et la ville. Paris: Flammarion, 1995.

EMPLASA, Empresa Paulista de Planejamento Metropolitano S/A. Por Dentro da Região Metropolitana de São Paulo, 2011. Disponível em: < http://www.emplasa.sp.gov.br/emplasa/RMSP/rmsp.pdf>. Acesso: 05 fev. de 2015.

IBGE. Diretoria de Pesquisas, Coordenação de População e Indicadores Sociais. Estimativas da população residente com data de referência $1^{\circ}$ de julho de 2014. Diário Oficial da União, Brasília, DF, 28 ago. 2014.

LAMURE, C. Quelle auto dans la ville? Paris: Presses de l'École Nationale des Ponts et Chaussées, 1995.

LEMOS, André. Cibercultura e mobilidade. A era da conexão. Razón y Palabra, v. 41, 2005.

LEMOS, André. Cultura da Mobilidade. Revista Famecos. Porto Alegre, no 40, dezembro de 2009. p28-35. 


\section{Revista Nacional de Gerenciamento de Cidades}

METRO. Companhia do Metropolitano de São Paulo. Informações sobre o sistema/situação em fevereiro/2015. 2015. Disponível em: <http://www.metro.sp.gov.br/metro/numeros-pesquisa/estruturafisica.aspx> Acesso em: 24 abri.2015.

ONU, Organização das Nações Unidas. UN-HABITaT. The United Nations perspective on reinventing planning. 2007 , p. 15-34

RIGHI, Roberto; DINIS, Henrique. O Automóvel e o Desenvolvimento Regional Metropolitano de São Paulo, Brasil. BALEIRAS, Rui Nuno. Casos de Desenvolvimento Regional. Cascais, Portugal: Principia, 2011. Pg. 237 a 252.

SÃO PAULO. Governo do Estado; Metro. Pesquisa de Mobilidade da Região Metropolitana de São Paulo. 2012.

SOUSANIS, John. World Vehicle Population Tops 1 Billion Units. Ward AutoWorld. 18 ago. 2011.

VALLE, Caio do. Aplicativo feito com dados da Prefeitura indica rotas para bikes. $\mathbf{O}$ Estado de $\mathbf{S}$. Paulo. 25 out. de 2014.

VASCONCELLOS, Eduardo Alcântara de. Mobilidade urbana e cidadania. Rio de Janeiro: Senac Nacional, 2012. 